\title{
Inhibitory Actions of Indomethacin on Electrical and Mechanical Responses Produced by Nerve Stimulation in Circular Smooth Muscle of the Guinea-Pig Gastric Fundus
}

\author{
Satoshi YonedA ${ }^{1 \#}$, Yoshihiko KITO $^{1}$ and Hikaru SUZUKI ${ }^{1}$ \\ ${ }^{1}$ Department of Physiology, Nagoya City University Medical School, Mizuho-ku, Nagoya \\ 467-8601, Japan \\ "Present: Department of Physiology II, Nara Medical School, Shijo-cyo, Kashiwara 634- \\ 8521, Japan
}

\begin{abstract}
The effects of indomethacin on electrical and mechanical responses produced by transmural nerve stimulation (TNS) were investigated in isolated circular smooth muscle of the guinea-pig gastric fundus. TNS evoked a cholinergic excitatory junction potential (e.j.p.). The e.j.p.s were inhibited by $1-10 \mu \mathrm{M}$ indomethacin, in a concentration-dependent manner, with no marked alteration of the resting membrane potential. Exogenously applied acetylcholine caused a depolarization of the membrane that was not altered by indomethacin. TNS evoked a cholinergic twitch contraction at low frequencies $(0.1 \mathrm{~Hz})$. A train of TNS's at high frequency $(1 \mathrm{~Hz})$ produced a transient contraction with a subsequent sustained relaxation. Indomethacin reduced the resting tension and inhibited these TNSinduced contractions. Application of $\mathrm{N}^{\omega}$-nitro-L-arginine (NOLA), an inhibitor of nitric oxide (NO) synthesis, increased the amplitude of twitch contractions, and altered transient contractions to tetanic contractions during TNS at a frequency of $1 \mathrm{~Hz}$, also with an increased amplitude. In the presence of NOLA, indomethacin $(5 \mu \mathrm{M})$ again reduced the resting tension and inhibited TNS-induced contractions. This inhibition was greater for twitch contractions than for tetanic contractions. Nifedipine reduced the TNS-induced contractions, while addition of indomethacin further reduced the amplitude of contractions. Contractions produced by low concentrations of acetylcholine $(0.1 \mu \mathrm{M})$ were inhibited by indomethacin, while those produced by $1 \mu \mathrm{M}$ were not. These results indicate that the inhibitory actions of indomethacin on TNS-induced contractions do not involve enhanced production of NO or selective inhibition of voltage-gated Ca-channels. Prejunctional autoregulatory mechanisms may also not be altered by indomethacin. As indomethacin inhibits the enzyme cyclooxygenase, it is speculated that endogenously produced prostaglandins exert excitatory actions on gastric smooth muscle, and act mainly postjunctionally to facilitate spontaneous and neurogenic electrical and mechanical activity.
\end{abstract}

Key words: gastric muscle, indomethacin, excitatory junction potential, contraction, nerve stimulation

Correspondence to: H. Suzuki, Department of Physiology, Nagoya City University Medical School, Mizuhoku, Nagoya 467-8601, Japan

Phone: +81-52-853-8129 Fax: +81-52-842-1538 e-mail: hisuzuki@med.nagoya-cu.ac.jp 


\section{Introduction}

Indomethacin is clinically important as an anti-inflammatory drug (Lewis and Furst, 1987). This chemical is commonly used as an inhibitor of cyclooxygenase. The digestive dysfunction which occurs as a side effect following oral ingestion of indomethacin is mainly the result of impairment of the protective functions of the mucosa due to a reduced production of prostanoids (Insel, 1991). In isolated smooth muscle, the concentration of indomethacin required to inhibit production of prostanoids is in the order of 1-10 $\mu \mathrm{M}$ (Lewis and Furst, 1987). In vascular tissues, however, indomethacin is a Ca-antagonist at these concentrations due to inhibition of $\mathrm{Ca}^{2+}$ influx through voltage-gated Ca-channels (Northover, 1977). Thus indomethacin may have multiple actions on smooth muscle.

We have investigated the actions of indomethacin on electrical and mechanical responses produced by transmural nerve stimulation (TNS) in isolated circular smooth muscle of the guinea-pig gastric fundus. The circular smooth muscle of the guinea-pig gastric fundus is electrically and mechanically quiescent, or occasionally produces small rhythmic activity. Electrical responses of the circular muscle of the gastric fundus evoked by transmural nerve stimulation (TNS) are atropine-sensitive excitatory junction potentials (e.j.p.s) but after inhibition with atropine, apamin-sensitive inhibitory junction potentials (i.j.p.s) become evident (Komori and Suzuki, 1986; Ohno et al., 1996). The effects of indomethacin on cholinergic transmission were evaluated from junction potentials recorded using intracellular microelectrodes. TNS also produces contractions in fundus smooth muscle, and a single TNS or a train of TNS's at low frequency $(<0.2 \mathrm{~Hz})$ produces a twitch contraction in response to each TNS (Komori and Suzuki, 1988). TNS at high frequency $(>1 \mathrm{~Hz})$ produces a transient contraction, which is changed to a tetanic contraction after inhibiting the production of nitric oxide (NO) with nitroarginine (Yoneda and Suzuki, 2001b). Experiments were also carried out to investigate the effects of indomethacin on twitch or tetanic contractions produced by TNS. The results indicate that in circular smooth muscle of the guinea-pig gastric fundus, indomethacin inhibits TNS-induced electrical and mechanical responses, possibly by mechanisms other than an increased production of NO or selective inhibition of voltage-gated Ca-channels. A preliminary part of this work was reported to the 78th annual meeting of the Japanese Physiological Society (Yoneda and Suzuki, 2001a).

\section{Methods}

Albino male guinea pigs, weighing 200-250 g, were anesthetized with fluoromethyl 2,2,2trifluoro-1-(trifluoromethyl) ethyl ether (sevoflurane; Maruishi Pharm., Osaka, Japan), and then decapitated. The animals were treated ethically according to the guidelines for the Care and Use of Animals approved by the Physiological Society of Japan. The fundus region of the stomach was isolated, and the mucosal layer removed using fine scissors. Small segments of circular smooth muscle tissue (1.0-1.5 mm wide, $2.5-3.0 \mathrm{~mm}$ long) were dissected together with the adherent longitudinal smooth muscle layer.

Isolated muscle strips were mounted on a silicone rubber plate fixed at the bottom of the 
recording chamber, with the mucosal layer uppermost, and immobilized by fine pins (diameter, $0.1 \mathrm{~mm}$ ). The rectangular recording chamber, which was made from Lucite plate, measured 8.0 $\times 20.0 \mathrm{~mm}$ with a depth of $5.0 \mathrm{~mm}$ and a capacity of about $1.0 \mathrm{ml}$. The muscle strips were superfused with warmed $\left(35^{\circ} \mathrm{C}\right)$ Krebs solution at a constant flow rate of about $3 \mathrm{ml} / \mathrm{min}$. Electrical responses were recorded from circular smooth muscle cells using a conventional microelectrode technique, with a glass capillary microelectrode filled with $3 \mathrm{M} \mathrm{KCl}$ (tip resistance: $50-80 \mathrm{M} \Omega$ ). Intramural nerves were electrically stimulated using the point stimulation method (Komori and Suzuki, 1986). Briefly, a silver wire (diameter, $0.5 \mathrm{~mm}$ ) coated with enamel except at the tip, was attached gently to the end of the tissue, and brief electrical pulses (0.1-0.5 ms duration, 10-30 V intensity) were applied to the tissue. Selective excitation of intramural nerves during this transmural nerve stimulation (TNS) was confirmed by the reversible inhibition of the TNS-induced electrical responses by $0.1 \mu \mathrm{M}$ tetrodotoxin.

Mechanical responses of the circular smooth muscle of the fundus were measured as follows. Both ends of the fundus circular smooth muscle strip (1.0-1.5 mm wide, $10-15 \mathrm{~mm}$ long) were tied with fine threads, and the strip mounted vertically in a cylindrical recording chamber (10.0 mm diameter, $20.0 \mathrm{~mm}$ high, capacity $2 \mathrm{ml}$ ). This was perfused with warmed $\left(35^{\circ} \mathrm{C}\right) \mathrm{Krebs}$ solution at a constant flow rate $(3 \mathrm{ml} / \mathrm{min})$. The lower end of the thread was fixed at the bottom, and the upper end was connected to a mechano-transducer (TB-612T, Nihon Kohden, Tokyo, Japan), and isometric mechanical responses measured in the direction of the circular muscle. A pair of silver plates $(2.0 \mathrm{~mm}$ wide, $20.0 \mathrm{~mm}$ long) was fixed opposite each other to the inner wall of the recording chamber, and electric pulses applied to the muscle strip to transmurally stimulate intramural nerves. Selective excitation of intramural nerves by these pulses was confirmed by the reversible inhibition of the evoked responses (twitch contractions) by $0.1 \mu \mathrm{M}$ tetrodotoxin.

The ionic composition of the Krebs solution was as follows (in $\mathrm{mM}$ ): $\mathrm{Na}+137.4, \mathrm{~K}+5.9, \mathrm{Ca}^{2+}$ 2.5, $\mathrm{Mg}^{2+} 1.6, \mathrm{HCO}_{3}^{-} 15.5, \mathrm{H}_{2} \mathrm{PO}_{4}^{-} 1.2, \mathrm{Cl}^{-} 134$, glucose 11.5 . The solution was aerated with $\mathrm{O}_{2}$ containing $5 \% \mathrm{CO}_{2}$, and $\mathrm{pH}$ of the solution was 7.2-7.3.

Drugs used were atropine sulphate, indomethacin, $\mathrm{N}^{\omega}$-nitro-L-arginine (NOLA) and tetrodotoxin (all purchased from Sigma Chem., MO, USA). Indomethacin was dissolved in a 5 $\mathrm{mM} \mathrm{Na} \mathrm{CO}_{3}$ solution at a concentration of $5 \mathrm{mM}$ as a stock solution, and diluted further with Krebs solution to prepare the desired concentration.

The values measured were expressed as the mean \pm standard deviation (S.D.), and differences tested using the Student's $t$-test. Probabilities of less than $5 \%(\mathrm{P}<0.05)$ were considered to be significant.

\section{Results}

\section{Effects of indomethacin on electrical responses}

In isolated smooth muscle tissue of the fundus, the resting membrane potential of smooth muscle cells was $-50.5 \pm 2.5 \mathrm{mV}(\mathrm{n}=12)$, which was maintained in the presence of $10 \mu \mathrm{M}$ indomethacin $(-50.1 \pm 2.8 \mathrm{mV}, \mathrm{n}=12, \mathrm{P}>0.05)$. However, the excitatory junction potential (e.j.p.) evoked by transmural nerve stimulation (TNS) was inhibited by 1-10 $\mu \mathrm{M}$ indomethacin, in a 
Control

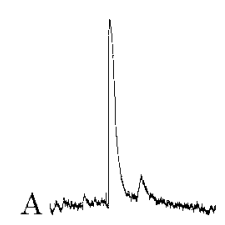
Indomethacin

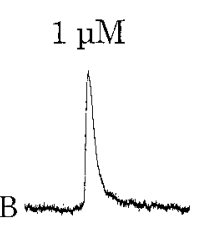

$$
3 \mu \mathrm{M}
$$<smiles>C[CH]C(C)C</smiles><smiles>[2H]C(C)CC(C)O</smiles>

$\mathrm{E}$

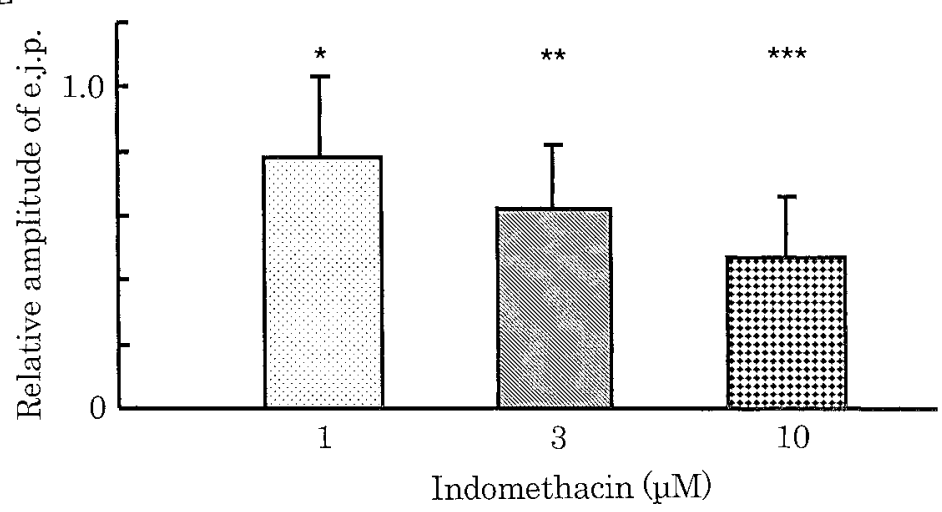

Fig. 1. Effects of indomethacin on e.j.p.s. A single e.j.p. was evoked by TNS ( $0.1 \mathrm{~ms}$ duration, $20 \mathrm{~V}$ intensity), in the absence (Control, A) and presence of indomethacin (B, $1 \mu \mathrm{M} ; \mathrm{C}$, $3 \mu \mathrm{M} ; \mathrm{D}, 10 \mu \mathrm{M})$. All e.j.p.s were recorded from the same cell. Indomethacin was applied cumulatively (20-25 min for every concentration). E, Summary of the effects of indomethacin on the amplitude of e.j.p.s. The amplitude of e.j.p.s was measured relative to that in the absence of indomethacin. Mean \pm S.D. $(n=8-15) . \quad{ }^{*} P<0.05$; ${ }^{*} \mathrm{P}<0.01 ;{ }^{* *} \mathrm{P}<0.001$.

concentration-dependent manner (Fig. 1). In the presence of $10 \mu \mathrm{M}$ indomethacin, the amplitude of an e.j.p. was reduced to about half (Fig. 1, E). The e.j.p.s were not altered ( $n=3$, data not shown) by the addition of $\mathrm{Na}_{2} \mathrm{CO}_{3}$ solution to the Krebs solution in an amount equivalent to that required for the preparation of the $10 \mu \mathrm{M}$ indomethacin-containing solution. This suggests that the inhibition was mainly due to the actions of indomethacin. The inhibition of the e.j.p. by indomethacin was reversible, but this required more than 30 min washing with indomethacin-free solution ( $\mathrm{n}=5$, data not shown).

Application of a train of TNS's at high frequencies (1-2 Hz) evoked e.j.p.s with successively decreasing amplitude (the depression phenomenon), confirming previously reported observations (Yoneda and Suzuki, 2001b). Figure 2 shows the effects of $3 \mu \mathrm{M}$ indomethacin on the e.j.p.s evoked by a train of 10 TNSs at a frequency of $1 \mathrm{~Hz}$. These TNS's elicited a weak depression phenomenon in the e.j.p.s, with indomethacin reducing the amplitude of all e.j.p.s to a similar extent (Fig. 2, A and B). When the amplitude of individual e.j.p.s was expressed relative to the first e.j.p. of the train of responses, indomethacin did not show a significant alteration of the depression phenomenon of e.j.p.s (Fig. 2, C). 
Control

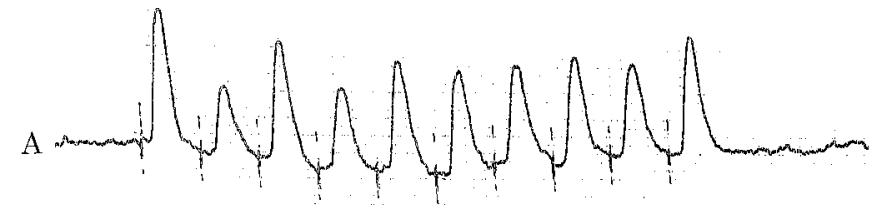

Indomethacin $3 \mu \mathrm{M}$

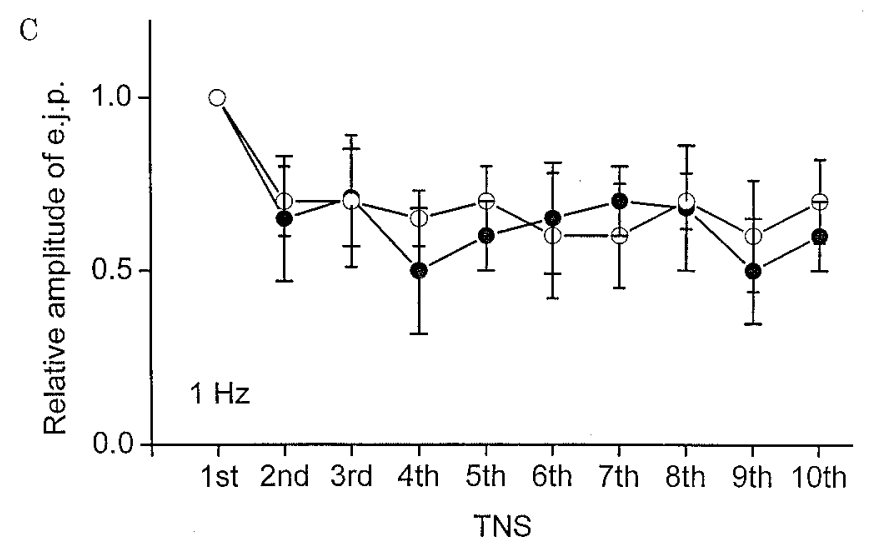

Fig. 2. Effects of indomethacin on e.j.p.s produced by repetitive TNS. A train of TNS (0.1 ms duration, $20 \mathrm{~V}$ intensity) was applied for 10 times at $1 \mathrm{~Hz}$ frequency, and e.j.p.s were recorded in the absence (A, Control) and presence of $3 \mu \mathrm{M}$ indomethacin (B). A and B were recorded from the same cell. $\mathrm{C}$, The relative amplitude of e.j.p.s was expressed by comparison with the first of each train response, and mean values $( \pm$ S.D., $n=9$ ) were plotted ( Control; $\bigcirc$, indomethacin).

Thus, indomethacin inhibits the amplitude of e.j.p.s without altering the depression phenomenon, suggesting that this inhibition was mainly a postjunctional event. If this is the case, it might be expected that the depolarization produced by exogenously applied acetylcholine (ACh) might be inhibited by indomethacin. Experiments were developed further to test the effects of indomethacin on the ACh-induced depolarization in the circular smooth muscle of the guinea-pig gastric fundus. ACh $(0.1$ and $1 \mu \mathrm{M})$ depolarized the membrane $(0.1$ $\mu \mathrm{M}, 4.0 \pm 2.1 \mathrm{mV}, \mathrm{n}=11 ; 1 \mu \mathrm{M}, 8.6 \pm 1.6 \mathrm{mV}, \mathrm{n}=8)$. These values were not altered in the presence of $10 \mu \mathrm{M}$ indomethacin $(0.1 \mu \mathrm{M}, 3.3 \pm 2.1 \mathrm{mV}, \mathrm{n}=5, \mathrm{P}>0.05 ; 1 \mu \mathrm{M}, 7.8 \pm 2.2 \mathrm{mV}, \mathrm{n}=10, \mathrm{P}>0.05)$. Thus it does not appear that indomethacin inhibits postjunctional cholinergic mechanisms in fundus smooth muscle. 


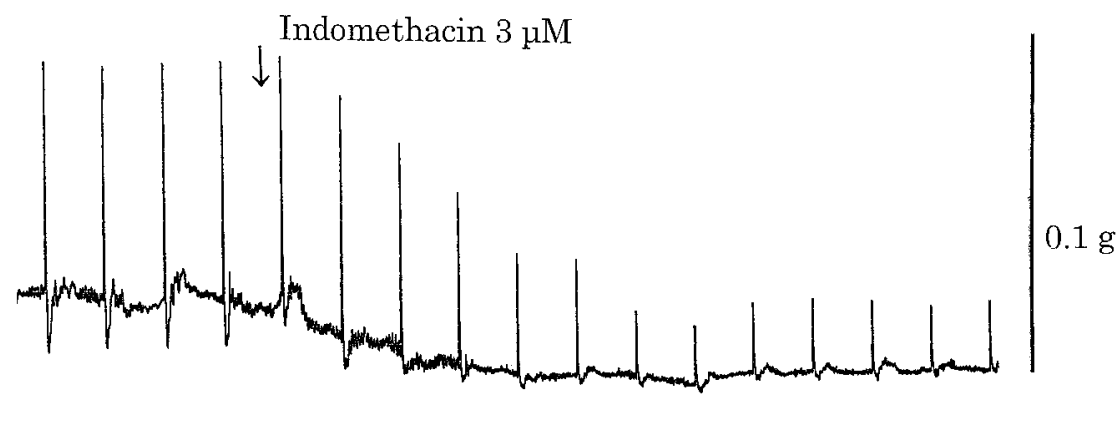

$10 \mathrm{~min}$

Fig. 3. Effects of indomethacin on twitch contractions. In isolated circular smooth muscle tissue of the guinea-pig stomach fundus, twitch contractions were evoked by application of TNS every $5 \mathrm{~min}$, while $3 \mu \mathrm{M}$ indomethacin was applied at the arrow. TNS: $0.2 \mathrm{~ms}$ duration, $100 \mathrm{~V}$ intensity.

\section{Effects of indomethacin on TNS-induced mechanical responses}

In isolated fundus smooth muscle, single TNS produced a twitch contraction. A train of 310 TNS's at a frequency of $0.1 \mathrm{~Hz}$ elicited twitch contractions in response to individual TNSs, mostly with a successive decrease in amplitude. A train of TNS's with $1 \mathrm{~Hz}$ frequency for $30 \mathrm{~s}$ produced a transient contraction and a following relaxation. These TNS-induced contractions were either abolished or sometimes converted to relaxation responses by application of $1 \mu \mathrm{M}$ atropine. The TNS-induced contractions were also abolished reversibly by tetrodotoxin $(0.1$ $\mu \mathrm{M})$. This suggests that they were produced by ACh released in response to excitation of intramural cholinergic nerves. These properties of TNS-induced contractions supported previous observations (Komori and Suzuki, 1988; Yoneda and Suzuki, 2001b).

A single TNS evoked a twitch contraction followed by a transient relaxation. When indomethacin $(3 \mu \mathrm{M})$ was applied while continuing single TNS every $5 \mathrm{~min}$, the amplitude of the twitch contractions was successively reduced, with an associated reduction in the resting tension. The inhibition of twitch contractions reached a stable level within a period of $20 \mathrm{~min}$ of superfusion of the preparation with indomethacin-containing solution (Fig. 3). The reduction in amplitude of the twitch contraction was between 10 and $30 \%$ of control (mean, $14 \pm 4 \%, n=8$ ) during inhibition by indomethacin. This inhibition did not recover until preparations had been washed for up to $2 \mathrm{hr}$ with an indomethacin-free solution $(\mathrm{n}=2)$.

In fundus smooth muscle, TNS causes the release of nitric oxide (NO) together with ACh and unidentified inhibitory transmitter substances (Yoneda and Suzuki, 2001b). Therefore, experiments were designed to test the effects of indomethacin in the presence of NOLA, an inhibitor of NO synthesis (Moncada et al., 1991). TNS was applied in trains at both $0.1 \mathrm{and} 1 \mathrm{~Hz}$ frequencies, since these two frequencies of TNS could produce typical twitch and tetanic contractions in this preparation (Yoneda and Suzuki, 2001b). In the presence of $10 \mu \mathrm{M}$ NOLA, the amplitude of the twitch contraction was increased to $159 \pm 52 \%$ ( $n=14)$ of control (Fig. 4, Ab). Addition of $3 \mu \mathrm{M}$ indomethacin in the presence of NOLA resulted in a reduction in the 
Control NOLA $10 \mu \mathrm{M} \quad+$ Indomethacin

$3 \mu \mathrm{M}$

A $\quad 0.1 \mathrm{~Hz}$

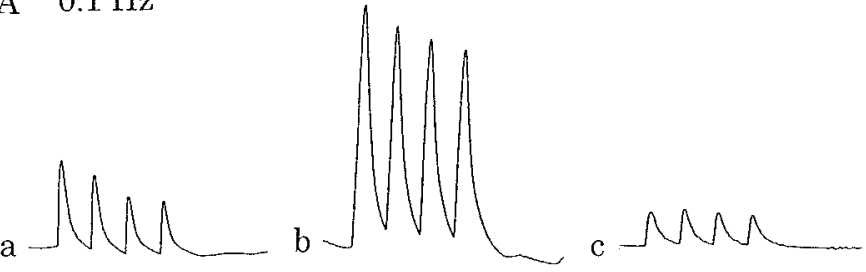

B $1 \mathrm{~Hz}$
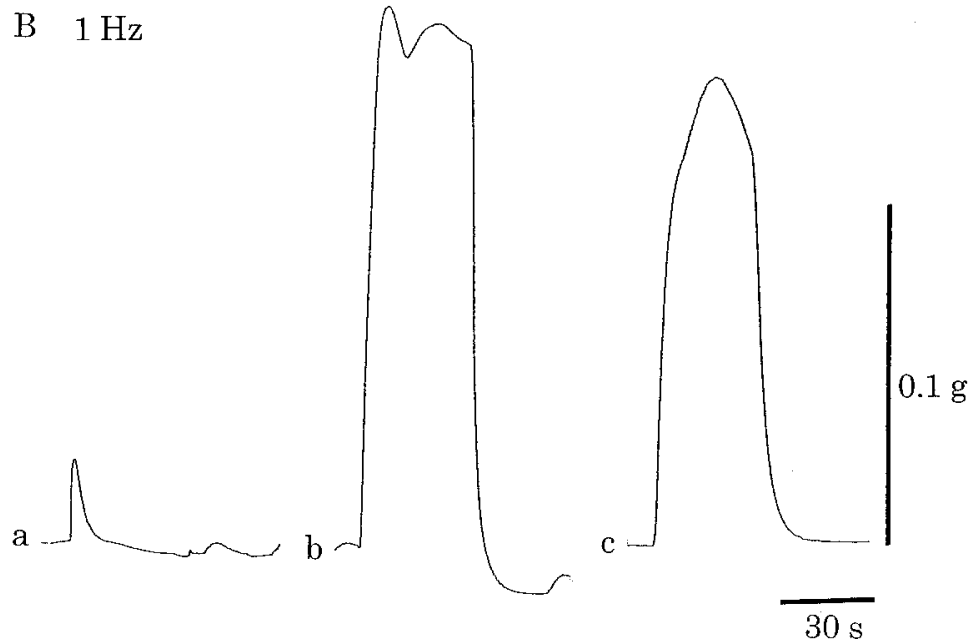

Fig. 4. Effects of inhibition of NO production on the actions of indomethacin. In isolated circular smooth muscle tissue of the guinea-pig fundus, TNS (1 ms duration, $100 \mathrm{~V}$ intensity) was applied for 4 trains of $0.1 \mathrm{~Hz}$ frequency (A) and for 30 trains of $1 \mathrm{~Hz}$ frequency (B), in the absence (a, Control), and in the presence of $10 \mu \mathrm{M}$ NOLA (b) and NOLA $+3 \mu \mathrm{M}$ indomethacin (c). All responses were recorded from the same tissue.

amplitude of twitch contractions to between 1-20\% of control (Fig. 5).

A train of TNS's at a frequency of $1 \mathrm{~Hz}$ for $30 \mathrm{~s}$ produced a transient contraction (Fig. 4, Ba); the peak amplitude was $139 \pm 52 \%(\mathrm{n}=14)$ of the twitch contraction produced by a single TNS. Indomethacin inhibited the amplitude of these contractions by about a half (Fig. 5). In the presence of NOLA, the transient contraction was changed to a tetanic contraction (Fig. 4, $\mathrm{Bb}$ ) with a peak amplitude which was increased to $263 \pm 92 \%(n=14)$ of that of a twitch contraction evoked in the absence of NOLA. In the presence of NOLA, addition of $3 \mu \mathrm{M}$ indomethacin again inhibited the contractions, but the inhibition was not as large as that seen with twitch contractions (Fig. 4, Bc). The summarized data (Fig. 5) indicated that the amplitude of tetanic contractions produced in the presence of NOLA and indomethacin was about two times larger than the twitch contractions elicited under control conditions. Indomethacin inhibited twitch 


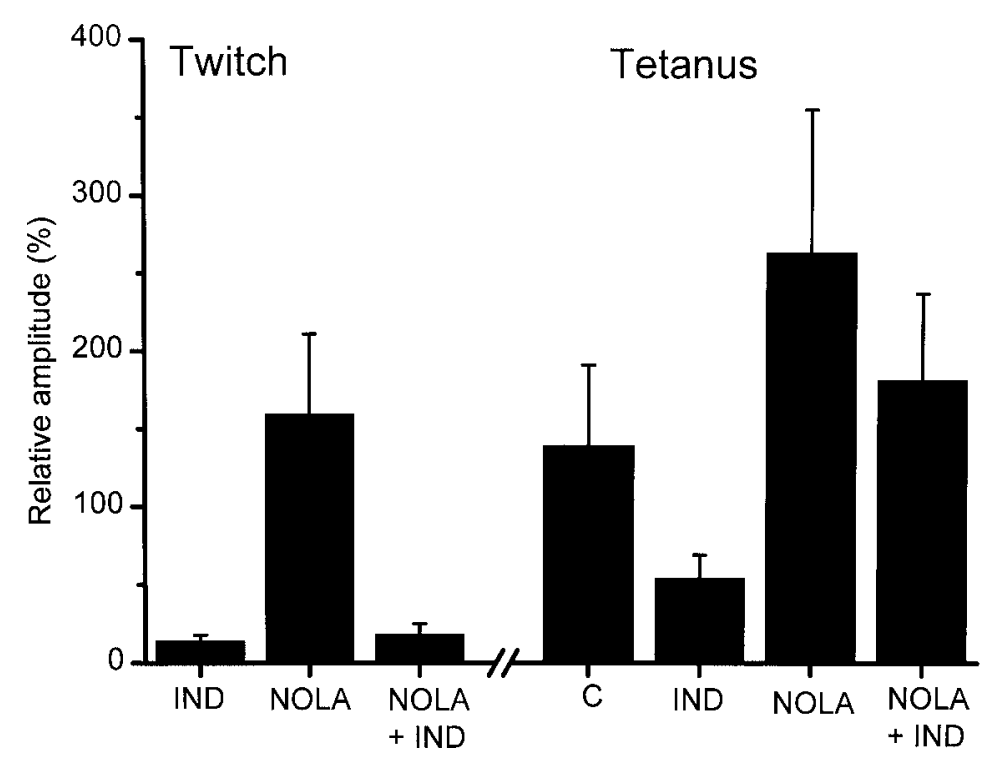

Fig. 5. Effects of NOLA and indomethacin on TNS-induced contractions. The circular smooth muscle was stimulated by $0.1 \mathrm{~Hz}$ and $1 \mathrm{~Hz}$ TNS trains to produce twitch and tetanic contractions, respectively, and the peak amplitudes measured relative to the twitch contractions evoked in the absence of NOLA or indomethacin. Mean \pm S.D. $(n=5-10)$. All values were significantly different from control $(\mathrm{P}<0.05)$. IND, $3 \mu \mathrm{M}$ indomethacin; NOLA, $10 \mu \mathrm{M}$; C, transient control contractions produced by trains of TNS at $1 \mathrm{~Hz}$ frequency for $30 \mathrm{~s}$ in the absence of NOLA and indomethacin.

contractions much more strongly than it did for tetanic contractions.

The possible involvement of Ca-antagonistic actions of indomethacin in the inhibition of TNS-induced contractions was investigated by using nifedipine, a dihydropyridine derivative inhibitor of voltage-gated L-type Ca-channels (Mori et al., 1999). In the presence of NOLA, nifedipine $(1 \mu \mathrm{M})$ reduced the amplitude of twitch and tetanic contractions to $50.2 \pm 7.8 \%$ ( $\mathrm{n}=5$ ) and $75.4 \pm 13.4 \%(n=5)$, respectively (Fig. 6, C). In the presence of nifedipine, together with NOLA, indomethacin further reduced the amplitude of twitch and tetanic contractions to $7.3 \pm$ $6.0 \%(n=4)$ and $27.5 \pm 10.6 \%(n=4)$ respectively of the contractions produced in the presence of NOLA alone (Fig. 6, D). These results collectively indicate that the inhibitory actions of indomethacin occur independently of the alteration of the activities of voltage-gated Cachannels. An increased production of NO by indomethacin would also be unlikely.

The effects of indomethacin on contractions produced by exogenously applied ACh were observed. ACh was applied at both 0.1 and $1 \mu \mathrm{M}$ concentrations. The lower concentration was considered to be comparable to that of nerve-derived ACh acting at the smooth muscle membrane (equal to $0.08 \mu \mathrm{M}$, Komori and Suzuki, 1988), while the higher concentration produced contractions similar to those produced by $1 \mathrm{~Hz}$ TNS in the presence of NOLA (105 \pm $58 \%, n=5)$. The amplitudes of contraction produced by both concentrations of ACh were not significantly altered by NOLA. Indomethacin significantly inhibited the contractions produced by $0.1 \mu \mathrm{M}$ ACh but not those elicited by $1 \mu \mathrm{M}$ ACh (Fig. 7). The results support the idea that 


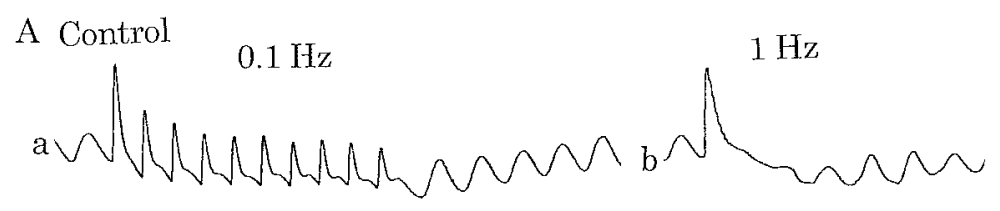

B NOLA $10 \mu \mathrm{M}$
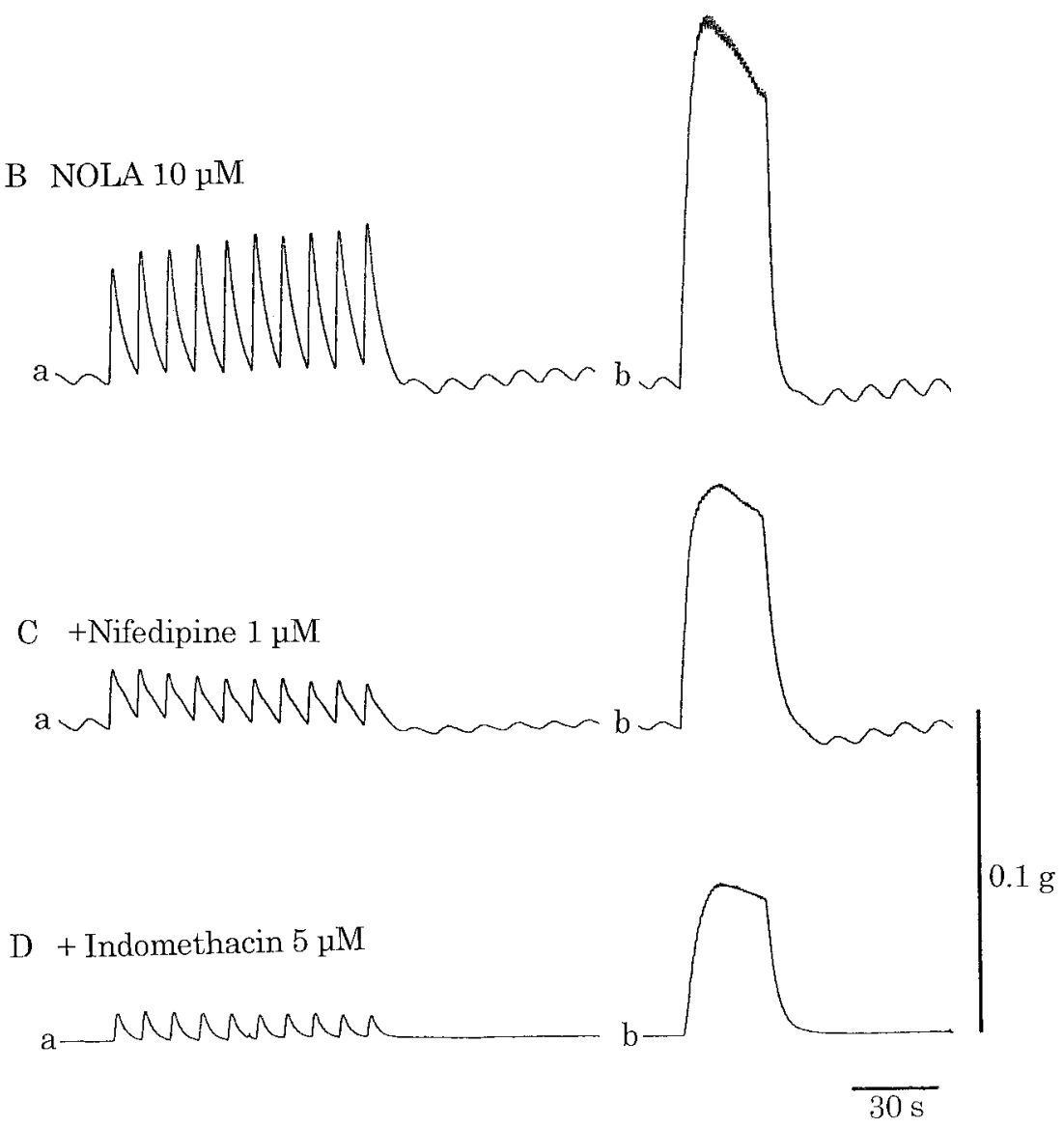

Fig. 6. Effects of NOLA and nifedipine on the actions of indomethacin. In isolated circular smooth muscle tissue of the guinea-pig gastric fundus, TNS (a, $0.1 \mathrm{~Hz}$ frequency, 10 times; b, $1 \mathrm{~Hz}$ frequency, 30 times) was applied in the absence (A, Control) and presence of $10 \mu \mathrm{M}$ NOLA (B), NOLA $+1 \mu \mathrm{M}$ nifedipine (C) and NOLA + nifedipine +5 $\mu \mathrm{M}$ indomethacin (D). All responses were recorded from the same tissue. TNS: $0.5 \mathrm{~ms}$ duration, $100 \mathrm{~V}$ intensity.

indomethacin has inhibitory actions on gastric smooth muscle. The inhibition of ACh-induced contraction by indomethacin appeared stronger for lower concentrations than for higher concentrations. 


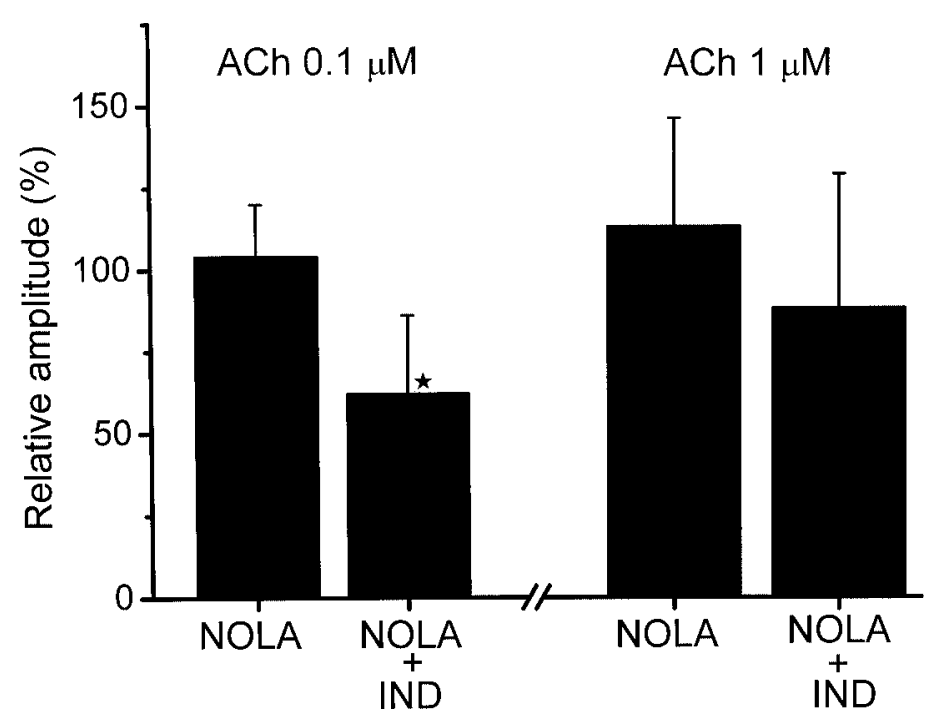

Fig. 7. Effects of indomethacin on ACh-induced contraction. Isolated circular smooth muscle of the guinea-pig gastric fundus were contracted by $\mathrm{ACh}(0.1$ and $1 \mu \mathrm{M})$, and the peak amplitude of contraction measured before and after application of $10 \mu \mathrm{M}$ NOLA or $\mathrm{NOLA}+5 \mu \mathrm{M}$ indomethacin (NOLA + IND). The amplitude of the ACh-induced contractions was measured relative to that in the absence of NOLA or indomethacin (mean \pm S.D., $\mathrm{n}=6-12)$. * significantly different from the control $(\mathrm{P}<0.05)$.

\section{Discussion}

The present experiments showed that in isolated circular smooth muscle of the guinea-pig gastric fundus, indomethacin inhibits e.j.p.s produced by TNS, with no significant alteration of the depression phenomenon. The depression phenomenon of e.j.p.s is considered to be due to successive reduction of the supply of $\mathrm{Ca}^{2+}$ required for transmitter release (Katz and Miledi, 1968). Therefore, the unaltered depression phenomenon by indomethacin suggests that the Camobilization processes at cholinergic nerve terminals may not be significantly attenuated by indomethacin. Prejunctional autoregulation mechanisms for the release of ACh are also one of the important factors which induce the depression phenomenon (Starke et al., 1989; Broadley, 1996). The lack of a significant alteration of the depression phenomenon by indomethacin suggests that the prejunctional cholinergic autoregulation mechanism may be not markedly altered. These results suggest that the inhibitory actions of indomethacin on the e.j.p. may be mainly postjunctional events. The depolarization of the membrane by exogenously applied ACh may be mainly a postjunctional event, and this was also not altered by indomethacin. Thus, consistent results were not obtained for the effects of indomethacin on the electrical responses of smooth muscle produced by TNS, and the mechanisms of inhibition of e.j.p.s. by indomethacin remain unclear.

Recently, it was proposed that the i.j.p.s recorded from smooth muscle cells in response to TNS are indirect via excitation of interstitial cells of Cajal (ICC) distributed in the gastric walls, through gap junctional transmissions (Publicover et al., 1993; Burns et al., 1996). Attenuation of 
e.j.p.s occurs in mice which lack functional ICC in their intestinal wall, which suggests that ICC have a role as an intermediary of cholinergic neurotransmission (Ward et al., 1997). In these cases, inhibition by indomethacin of the activity of ICC including gap junctional communication between these cells has to be considered. ICC have muscarinic receptors, and ACh-induced depolarization of smooth muscle may be also indirect, through depolarization of the membrane of ICC (Sanders et al., 1999). ICC are also rich in an enzyme NO synthase which produces NO from L-arginine (Bredt et al., 1990). The detailed properties of ICC remain unknown, and possible involvement of selective inhibition of ICC functions by indomethacin cannot be ruled out.

Inhibitory actions of indomethacin were also observed on the mechanical responses produced by TNS in gastric smooth muscle. This inhibition was seen in the presence of both NOLA and nifedipine. NOLA inhibits production of NO (Moncada et al., 1991), and in the absence of the production of NO the twitch contractions were augmented and the transient contractions produced by high frequency TNS were altered to tetanic contractions. These effects of NOLA indicate that TNS increases production of NO, together with the release of ACh from cholinergic nerves. The results are consistent with previous observations that NO is released in response to vagal excitation to participate the receptive relaxation of the guinea-pig stomach (Desai et al., 1991; Desai et al., 1994; Henning et al., 1997). In the presence of NOLA, indomethacin inhibits twitch and tetanic contractions, and these results indicate that the increased production of NO may not be the main factor involved in the indomethacin-induced inhibition. Nifedipine inhibits $\mathrm{Ca}^{2+}$ influx through voltage-gated L-type Ca-channels in many types of smooth muscle (Mori et al., 1996), suggesting that selective inhibition of these channels is unlikely to be involved in the inhibitory actions of indomethacin. This is inconsistent with the proposal that indomethacin has Ca-antagonistic actions in vascular smooth muscle (Northover, 1977).

There are many factors which modulate excitation-contraction coupling in smooth muscle, and inhibition of $\mathrm{Ca}^{2+}$ influx is one of the important factors (Karaki et al., 1997). Although the present experiments suggest that the inhibitory actions of indomethacin on fundus smooth muscle may be produced by mechanisms different from the inhibition of L-type Ca-channels, the cellular mechanisms of the indomethacin-induced inhibition of smooth muscle activity remain unclear. Similar inhibitory actions are also noted with suramin, a known antagonist of ATPreceptors (Dunn and Blakeley, 1988), in which suramin inhibits spontaneous mechanical activities of gastric smooth muscle without alteration of the electrical activities of the membrane (Xue et al., 1999). In considering the inhibitory actions of indomethacin on the enzyme cyclooxygenase (Lewis and Furst, 1987), it is reasonable to speculate that gastric smooth muscle has an elevated level of excitability as a result of the background production of excitatory prostaglandins. In the guinea-pig stomach, several types of prostaglandins, such as $\mathrm{E}_{1}$ and $\mathrm{F}_{2 \alpha}$ types, produce excitatory responses in smooth muscle (Mishima and Kuriyama, 1976; Sakamoto and Nasu, 1987). Inhibition of the production of prostaglandins by indomethacin would reduce the resting tension and also the excitability of smooth muscle to neurotransmitters. In this case, the actions of endogenous prostaglandins appear to occur mainly postjunctionally. 
The inhibitory actions of indomethacin are more marked on twitch contractions than on tetanic contractions. The amount of ACh released in response to a single TNS may be smaller than that released during a train of TNS's at a frequency of $1 \mathrm{~Hz}$. This is consistent with the differences noted with the indomethacin-induced inhibition of contractions produced by exogenously applied ACh, i.e., contractions produced by lower concentration of ACh were inhibited more than those produced by higher concentration of $\mathrm{ACh}$. It is reasonable to speculate that intracellular $\mathrm{Ca}^{2+}$ concentrations may be elevated more by a higher concentration of ACh than by a lower concentration of ACh. This may be the reason for the difference in the inhibition between twitch and tetanic contractions. These results could be reasonably explained if the inhibitory actions of indomethacin were the result of a lowering the intracellular $\mathrm{Ca}^{2+}$ concentration in smooth muscle cells, due to a decreased level of excitatory prostaglandins.

It is concluded that in circular smooth muscle of the guinea-pig stomach fundus, indomethacin inhibits TNS-induced electrical and mechanical responses. The inhibitory actions of indomethacin do not involve the increased production of NO, activation of prejunctional cholinergic autoregulation mechanisms, or the inhibition of L-type Ca-channels. Although the present experiments could not clearly indicate the possible mechanisms of these actions of indomethacin, a reduction in the level of endogenously produced excitatory prostaglandins is considered. Clinically, gastrointestinal complaints such as anorexia, nausea and abdominal pain appear as one of the side effects of indomethacin ingestion (Insel, 1991). The present experiments suggest that the depression of the vagal control of gastric smooth muscle may be also involved in these indomethacin-induced disorders.

\section{References}

Bredt, D.S., Hwang, P.M. and Snyder, S.H. (1990). Localization of nitric oxide synthase indicating a neural role for nitric oxide. Nature 347: 768-770.

Broadley, K.J. (1996). Autonomic Pharmacology. Taylor \& Francis, London, UK.

Burns, A.J., Lomax, A.E.J., Torihashi, S., Sanders, K.M. and Ward, S.M. (1996). Interstitial cells of Cajal mediate inhibitory neurotransmission in the stomach. Proc. Natl. Acad. Sci. USA 93: 1200812013.

Desai, K.M., Sessa, W.C. and Vane, J.R. (1991). Involvement of nitric oxide in the reflex relaxation of the stomach to accommodate food or fluid. Nature 351: 477-479.

Desai, K.M., Warner, T.D., Bishop, A.E., Polak, J.M. and Vane, J.R. (1994). Nitric oxide, and not vasoactive intestinal peptide, as the main neurotransmitter of vagally induced relaxation of the guinea-pig stomach. Br. J. Pharmacol. 113: 1197-1202.

Dunn, P.M. and Blakeley, A.G.H. (1988). Suramin: a reversible P2-purinoceptor antagonist in the mouse vas deferens. Br. J. Pharmacol. 93: 243-245.

Furness, J.B. and Costa, M. (1987). The Enteric Nervous System. Churchill-Livingstone, Edinburgh, UK.

Hennig, G., Brookes, S.J.H. and Costa, M. (1997). Excitatory and inhibitory motor effluxes in the isolated guinea-pig stomach. J. Physiol. (London) 501: 197-212.

Insel, P.A. (1991). Analgesic-antipyretics and anti-inflammatory agents; drugs employed in the treatment of rheumatoid arthritis and gout. In: The Pharmacological Basis of Therapeutics, ed. by A. Goodman Gilman, T.W. Rall, A.S.Nies \& P. Taylor, 8th Edition, Chapter 26, Pergamon Press, New York, U.S.A., pp. 638-681.

Karaki, H., Ozaki, H., Hori, M., Mitsui-Saito, M., Amano, K., Harada, K., Miyamoto, S., Nakazawa, H., 
Won, K.J. and Sato, K. (1997). Calcium movements, distribution, and functions in smooth muscle. Pharmacol. Rev. 49: 157-230.

Katz, B. and Miledi, R. (1968). The role of calcium in neuromuscular facilitation. J. Physiol. (London) 195: 481-492.

Komori, K. and Suzuki, H. (1986). Distribution and properties of excitatory and inhibitory junction potentials in circular smooth muscle of the guinea-pig stomach. J. Physiol. (London) 370: 339355.

Komori, K. and Suzuki, H. (1988). Modulation of smooth muscle activity by excitatory and inhibitory nerves in the guinea-pig stomach. Comp. Biochem. Physiol. 91C: 311-319.

Lewis, A.J. and Furst, D.W. (1987). Nonsteroidal Antiinflammatory Drugs: Mechanisms and Clinical Use. Marcel Dekker, New York.

Mishima, K. and Kuriyama, H. (1976). Effects of prostaglandins on electrical and mechanical activities of the guinea-pig stomach. Jpn. J. Physiol. 26: 537-548.

Moncada, S., Palmer, R.M. and Higgs, E.A. (1991). Nitric oxide: physiology, pathophysiology, and pharmacology. Pharmacol. Rev. 43: 109-142.

Mori, Y., Mikala, G., Varadi, G., Kobayashi, T., Koch, S., Wakamori, M. and Schwartz, A. (1996). Molecular pharmacology of voltage-dependent calcium channels. Jpn. J. Pharmacol. 72: 83-109.

Northover, B.J. (1977). Indomethacin-a calcium antagonist. Gen. Pharmacol. 8: 293-296.

Ohno, N., Xue, L., Yamamoto, Y. and Suzuki, H. (1996). Properties of inhibitory junction potential in smooth muscle of the guinea-pig gastric fundus. Br. J. Pharmacol. 117: 974-978.

Publicover, N.G., Hammond, E.M. and Sanders, K.M. (1992). Amplification of nitric oxide signaling by interstitial cells isolated from canine colon. Proc. Natl. Acad. Sci. USA 90: 2087-2091.

Sakamoto, Y. and Nasu, Y. (1987). Electrical and mechanical interaction between circular and longitudinal muscle layers of the guinea-pig stomach. J. Smooth Muscle Res. 23: 67-73.

Sanders, K.M., Örgög, T., Koh, S.D., Torihashi, S. and Ward, S.M. (1999). Development and plasticity of interstitial cells of Cajal. Neurogastroenterol. Mot. 11: 311-338.

Sanders, K.M. and Ward, S.M. (1992). Nitric oxide as a mediator of nonadrenergic noncholinergic neurotransmission. Am. J. Physiol. 262: G379-G392.

Starke, K., Göthert, M. and Kilbinger, H. (1989). Modulation of neurotransmitter release by presynaptic autoreceptors. Physiol. Rev. 69: 864-989.

Ward, S.M., Harney, S.C., Bayguinov, J.R., McLaren, G.J. and Sanders, K.M. (1997). Development of electrical rhythmicity in the murine gastrointestinal tract is specifically encoded in the tunica muscularis. J. Physiol. (London) 505: 241-258.

Xue, L., Imaeda, K., Yamamoto, Y. and Suzuki, H. (1998). Effects of suramin on electrical and mechanical activities in antrum smooth muscle of the guinea-pig stomach. J. Autonom. Pharmacol. 18: 325331.

Yoneda, S. and Suzuki, H. (2001a). Inhibition by nitric oxide of cholinergic transmission in the guineapig stomach. Jpn. J. Physiol. Suppl. 51 (in press).

Yoneda, S. and Suzuki, H. (2001b). Nitric oxide inhibits smooth muscle responses evoked by cholinergic nerve stimulation in the guinea-pig gastric fundus. Jpn. J. Physiol. 51 (in press).

(Received September 10, 2001: Accepted October 15, 2001) 